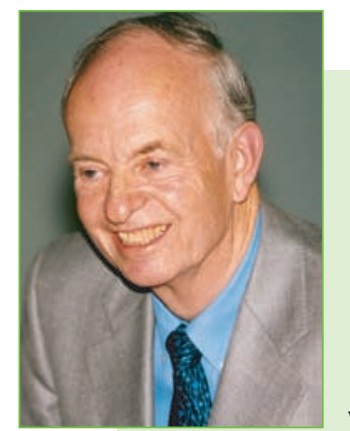

\title{
Über die Schönheit der Töchter der Göttin Flora
}

Warum beschäftigt sich der Mensch seit uralten Zeiten mit Pflanzen, mit blühenden Sujets seiner Umgebung? Sind es die pflanzlichen Produkte, die als Nahrungsmittel, als Rauschmittel oder als Phytopharmaka genutzt werden? Oder sind es die vielfältigen Düfte und Geschmäcker, die das Leben lebenswert machen? Vielleicht sind es Bruchteile von allen Eigenschaften, die die Blütenpflanzen ausmachen.

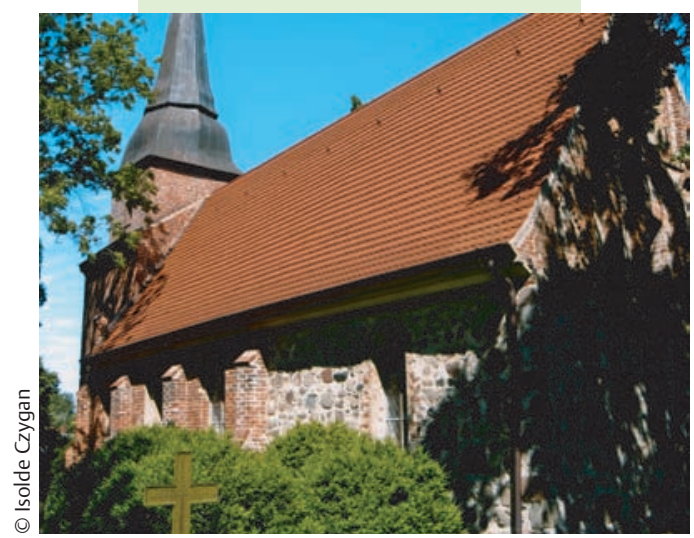

Mellenthiner Kirche (Insel Usedom) mit mittelalterlichen Fresken.
Ich meine, wir dürfen auch nicht vergessen, dass Pflanzen in ihrer geistigen Schönheit eine besondere Aufgabe haben. Oft wird ihnen ein symbolhafter Charakter zugesprochen. Das lässt sich in vielfältiger Weise belegen. Beispiele dafür fand ich bei meinem Besuch auf der Insel Usedom in der mittelalterlichen Kirche zu Mellenthin.

Im Inneren befindet sich eine Vielzahl von christlich geprägten Blumen am Gestühl. Eine Auswahl zeigen die Abbildungen. Der Künstler, der die Türen naturgetreu bemalt hat, ist leider nicht bekannt. Der hohe Anteil an Marienpflanzen lässt fragen, ob diese Kirche ursprünglich Maria geweiht war. Jedenfalls zeigen uns diese Beispiele, wie natur- und geisteswissenschaftliche Fragen immer wieder miteinander verknüpft werden können.

Franz-Christian Czygan

\section{Editorial}

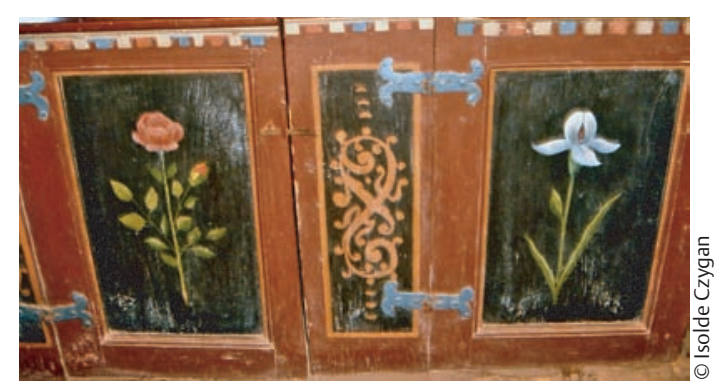

Rose (Rosa spec.) und Iris (Iris spec.) - beides Marienpflanzen.

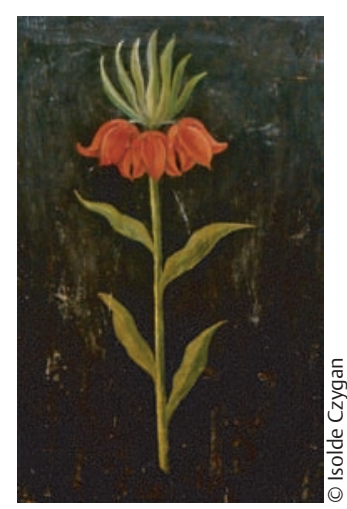

Kaiserkrone (Fritillaria imperialis L.; Marienpflanze).

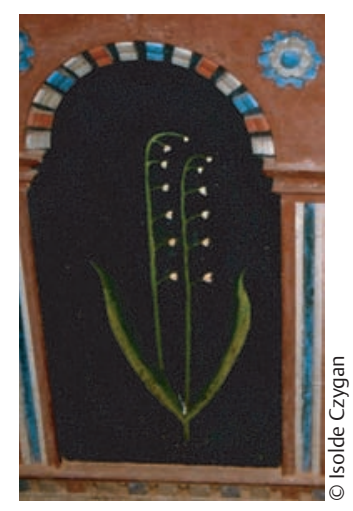

Maiglöckchen (Convallaria majalis L.; Marienpflanze und Pflanze des Kopernicus).

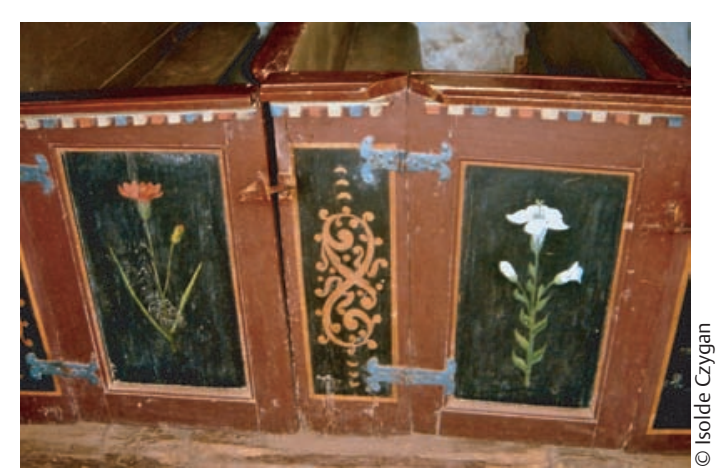

Nelke (Dianthus spec.) und Lilie (Lilium spec.) - beides Marienpflanzen. 